\title{
MULHERES NO FUTEBOL: ALTERAÇÕES NO REGULAMENTO DA CONMEBOL E ESPAÇO NA MÍDIA TELEVISIVA
}

\author{
Janice Zarpellon Mazo ${ }^{1}$ \\ Geórgia Fernandes Balardin ${ }^{2}$ \\ Giandra Anceski Bataglion ${ }^{3}$
}

Recebido em: 27/02/2020 Aprovado em: 20/04/2020

Resumo: Este estudo buscou identificar a ocorrência e as características das reportagens sobre o futebol feminino no programa de televisão "Globo Esporte - Rio Grande do Sul", nos anos de 2016 e 2017. Foram acompanhadas todas as edições do programa no referido período, sendo registradas as seguintes informações em termos das reportagens sobre o futebol feminino: tempo de duração, assunto abordado, equipe de reportagem, comentários realizados e observação de jogos. Posteriormente, foi computado o número de reportagens em cada ano. Os resultados mostraram que houve um aumento de $84 \%$ no número de reportagens quando comparados os dois anos. O mesmo ocorreu com o tempo de duração das reportagens. No ano de 2017, reportagens com entrevistas de atletas e comissão técnica fizeram parte do programa, assim como comentários e gols dos principais jogos dos clubes Sport Club Internacional e Grêmio Futebol Porto-Alegrense (GreNal). Ademais, foi criado o quadro "Joga que nem mulher" que proporcionou maior visibilidade ao futebol feminino no programa televisivo investigado. Notou-se que mudanças no regulamento da Confederação Sul-Americana de Futebol (CONMEBOL), divulgadas no ano de 2016, contribuíram para a conquista de maior espaço às mulheres do futebol no programa Globo Esporte - Rio Grande do Sul a partir de 2017.

Palavras-chave: Mulheres; Futebol; CONMEBOL; Mídia Esportiva; Jornalismo Esportivo.

Abstract: This study sought to identify the occurrence and characteristics of the reports on women's football on the television program "Globo Esporte - Rio Grande do Sul", in the years 2016 and 2017. All editions of the program in that period were monitored, being the following information was recorded in terms of the reports on women's football: duration, subject matter, reporting team, comments made and observation of games. Subsequently, the number of reports in each year was computed. The results showed that there was an increase of $84 \%$ in the number of reports when compared to the two years. The same occurred with the duration of the reports. In 2017, reports with interviews of athletes and coaching staff were

\footnotetext{
${ }^{1}$ Professora Doutora da Escola de Educação Física, Fisioterapia e Dança (ESEFID) e do Programa de PósGraduação em Ciências do Movimento Humano (PPGCMH), da Universidade Federal do Rio Grande do Sul (UFRGS). E-mail: janice.mazo@ufrgs.br. Orcid: https://orcid.org/0000-0002-8215-0058.

${ }^{2}$ Licenciada e Bacharela em Educação Física pela Escola de Educação Física, Fisioterapia e Dança (ESEFID), da Universidade Federal do Rio Grande do Sul (UFRGS). E-mail: georgiabalardin@gmail.com. Orcid: https://orcid.org/0000-0001-9994-9694.

${ }^{3}$ Doutoranda no Programa de Pós-Graduação em Ciências do Movimento Humano (PPGCMH), da Universidade Federal do Rio Grande do Sul (UFRGS). E-mail: giandraanceski@gmail.com. Orcid: https://orcid.org/00000001-8913-9874.
} 
part of the program, as well as comments and goals from the main games of the clubs Sport Club Internacional e Grêmio Futebol Porto-Alegrense (GreNal). In addition, the "Play as a woman" board was created, which provided greater visibility to women's football in the investigated television program. It was noted that changes in the South American Football Confederation (CONMEBOL), regulations, released in 2016, contributed to the achievement of greater space for women in football in the Globo Esporte - Rio Grande do Sul program from 2017.

Keywords: Women; Soccer; CONMEBOL; Sports Media; Sports Journalism.

Resumen: Este estudio buscó identificar la ocurrencia y las características de los informes sobre fútbol femenino en el programa de televisión "Globo Esporte - Rio Grande do Sul", en los años 2016 y 2017. Todas las ediciones del programa en ese período fueron monitoreadas, siendo que se registró la siguiente información en términos de los informes sobre el fútbol femenino: duración, tema, equipo de informes, comentarios y observación de los juegos. Posteriormente, se calculó el número de informes en cada año. Los resultados mostraron que hubo un aumento del $84 \%$ en el número de informes en comparación con los dos años. Lo mismo ocurrió con la duración de los informes. En 2017, informes con entrevistas de atletas y entrenadores formaron parte del programa, así como comentarios y objetivos de los principales juegos de los clubes Sport Club Internacional e Grêmio Futebol Porto-Alegrense (GreNal). Además, se creó el tablero "Juega como mujer", que proporcionó mayor visibilidad al fútbol femenino en el programa de televisión investigado. Se observó que los cambios en las regulaciones de Confederación Sudamericana de Fútbol (CONMEBOL), lanzados en 2016, contribuyeron al logro de un mayor espacio para las mujeres en el fútbol en el programa Globo Esporte - Rio Grande do Sul a partir de 2017.

Palabras clave: Mujeres; Fútbol; CONMEBOL; Medios Deportivos; Periodismo Deportivo.

\section{Considerações iniciais}

Os meios de comunicação de massa, as mídias, assumem um papel de produção de modos de existência, organizando fluxos de acontecimentos e espetáculos sob diferentes perspectivas, as quais podem ser dramáticas, sensacionalistas, produzindo emoções, despertando identidades, criando imaginários e construindo uma interpretação de mundo (COIMBRA, 2001). As mídias exercem influência constante e decisiva na cultura corporal de movimento, informando e ditando formas, construindo novos significados e modalidades de entretenimento e consumo, em especial, no caso do esporte (MAZZOCATO et al., 2012). Os programas esportivos são hoje, no mercado televisivo, um aliado das redes de televisão, aspecto importante na audiência das emissoras. Há um crescimento na divulgação desses programas, principalmente pelo esporte espetáculo, no entanto, o futebol feminino parece não ter a mesma repercussão na mídia que a modalidade do futebol masculino (MAZZOCATO et al., 2012).

A realidade é complexa e revela um cenário com disparidades e dificuldades. Para as marcas investirem em uma modalidade, elas se baseiam em três premissas: preço, prazo e 
audiência. Ainda que o campeonato feminino de futebol possa garantir essa tríade, os anunciantes não entendem dessa forma (ALBUQUERQUE, 2017). As empresas mostram pouco interesse em investir no futebol feminino quando comparado ao futebol masculino. Isto cria um círculo desfavorável: o público não participa porque não tem a mídia, a mídia não investe porque não tem patrocinador e o patrocinador não investe porque não tem o público e a mídia. Nesse sentido, conforme Patiño (2011), o futebol feminino carece de profundas modificações socioculturais, de modo a ressignificar práticas e representações que acompanham o fenômeno.

Quando olhamos os dados de 2017, no Campeonato Brasileiro de Futebol Feminino Série A1 e A2, observam-se que dos 140 jogos disponíveis, somente 40 foram comprados pelas empresas de televisão, sendo que 15 jogos foram transmitidos ao vivo. Realidade bem diferente do Campeonato Brasileiro de Futebol Masculino, que pertence ao maior grupo de televisão, único à frente dos direitos e que transmite todos os 380 jogos do campeonato. Em 2017, por exemplo, os seis anunciantes desembolsaram R\$ 283 milhões, cada um, para veicular suas marcas nos estádios e durante as transmissões do Campeonato Brasileiro de Futebol Masculino na televisão. Enquanto isso, no mesmo ano, a única patrocinadora do Campeonato Brasileiro Feminino, desembolsou R\$ 10 milhões (ALBUQUERQUE, 2017).

O baixo interesse das emissoras de televisão na compra dos direitos de imagem dos jogos e o número de patrocinadores dos times femininos contribuem para a dificuldade de expansão do futebol feminino no país. No caso da Rede Globo, uma das grandes emissoras de telecomunicação do país, dedica de 8 a $9 \%$ da programação líquida para programas esportivos que tem como base o futebol masculino. Fato relacionado com o potencial do esporte para aumentar a audiência, viabilizando o caráter econômico, existente por parte das empresas de telecomunicação, que gera negócios (AGUIAR; PROCHNIK, 2010).

A alteração do regulamento de Licença dos Clubes, da Confederação Sul-Americana de Futebol (CONMEBOL), apresentado no dia 30 de setembro de 2016, suscitou expectativa de mudanças nos investimentos. O regulamento determinou que o solicitante $-\mathrm{o}$ clube $-\mathrm{de}$ futebol, tenha uma equipe principal feminina e, pelo menos, uma categoria juvenil feminina ou deve estar associado a um clube que às tenham (CONMEBOL, 2018). A CONMEBOL deu um prazo de dois anos para se processarem as adequações. Desta forma, a medida passou a ser válida a partir de 2019, devendo todas as equipes brasileiras masculinas disporem de uma equipe feminina. Em caso de descumprimento do regulamento, as equipes masculinas poderiam ser impedidas de participar da Copa Sul-Americana e da Copa Libertadores (CONMEBOL, 2016). No ano de 2018, um ano antes do novo regulamento entrar em vigor, 
dos 20 clubes que participaram do Campeonato Brasileiro de Futebol Masculino, apenas oito possuíam equipes femininas.

Tendo em vista as mudanças anunciadas quanto ao regulamento de Licença dos Clubes, a partir do ano de 2017 houve incremento de investimento no futebol feminino no estado do Rio Grande do Sul. Assim sendo, conjecturamos que, provavelmente, a mídia dedicou mais espaço ao futebol feminino nos programas de televisão, particularmente, no "Globo Esporte - Rio Grande do Sul”. Foi selecionado este telejornal esportivo, o qual é exibido nas tardes de segunda-feira a sábado com 30 minutos de duração, devido a ampla audiência como também relevância no cenário esportivo estadual e por ser transmitido em canal aberto.

Frente a tais considerações, este estudo buscou identificar a ocorrência e as características das reportagens sobre o futebol feminino no programa de televisão "Globo Esporte - Rio Grande do Sul”, nos anos de 2016 e 2017. Com o propósito de responder ao objetivo do estudo, foram verificadas, descritas e analisadas as edições do referido programa televisivo do gênero esportivo, o qual possui transmissão e alcance regional. Foram coletados dados no período que compreende o mês de janeiro de 2016 ao mês de dezembro de 2017, considerando que no ano de 2016 foi aprovado o Regulamento CONMEBOL e, no ano seguinte, os clubes Sport Club Internacional e Grêmio Futebol Porto-Alegrense restabeleceram os seus departamentos de futebol com os times femininos.

Os dados coletados foram anotados em planilhas de Excel, bem como se utilizou diário de bordo a fim de se potencializar o registro de informações acerca do objeto de estudo. Posteriormente, o material coletado foi submetido à análise temática de conteúdo (FLICK, 2009), sendo elaboradas as seguintes unidades de significado: a) Número de reportagens apresentadas em cada ano, de 2016 e 2017; b) Tempo de duração de cada reportagem; c) Assunto abordado: gols, melhores momentos; d) Equipe de reportagem presente nos treinos e/ou jogos; e) Reportagem com atleta específico; f) Reportagem com comissão técnica; g) Comentários sobre os jogos; h) Análise dos jogos apresentados. As informações obtidas são apresentadas e discutidas à luz de revisão bibliográfica realizada acerca do assunto investigado. A fim de melhor contextualizar nosso objeto de estudo, após estas considerações iniciais, organizamos o texto em sete tópicos, quais sejam: Futebol na Mídia Televisiva; Regulamento da CONMEBOL; Sport Club Internacional e o Futebol Feminino; Grêmio Futebol Porto-Alegrense e o Futebol Masculino; Regulamento, Obrigatoriedade e as Mulheres do Futebol na Mídia; Considerações Finais e, por fim; Referências. 


\section{Futebol na mídia televisiva}

A televisão constitui-se em um dos principais meios de comunicação de massa no Brasil. Segundo dados do último Censo realizado pelo Instituto Brasileiro de Geografia e Estatística (IBGE), os aparelhos de televisão estão presentes em 95,1\% dos domicílios brasileiros, algo que facilita, e muito, o acesso à informação (IG SÃO PAULO, 2012). Quase 90\% dos brasileiros se informam pela televisão sobre o que acontece no país, sendo que $63 \%$ têm na televisão o principal meio de informação (SECRETARIA DE COMUNICAÇÃO SOCIAL DA PRESIDÊNCIA DA REPÚBLICA, 2016).

Para a televisão, e para a mídia em geral, o esporte é uma fonte inesgotável de notícias, de público e de lucro. O momento da competição, propriamente dito, é apenas um "pré-texto" (KENSKI, 1995). No esporte feminino, encontramos uma quantidade pequena de jogos sendo transmitidos ao vivo em um canal aberto para as diferentes categorias. Mais recentemente, uma emissora adquiriu os direitos de transmissão do Campeonato Mundial de Futebol Feminino sub-17, sub-20 e profissional, todos ligados a seleção brasileira. Vale lembrar que nos jogos do Campeonato Brasileiro de Futebol Feminino do ano de 2017, série A1 e A2, somente 15 jogos foram transmitidos ao vivo de um total de 140 jogos. As partidas dos Jogos Olímpicos, comumente, entram na grade de programação das grandes emissoras. Quando observamos o futebol masculino, encontramos diariamente transmissões ao vivo em canais abertos e fechados para as categorias sub-20, sub-23 e profissional dos diferentes clubes e seleção brasileira.

Novas e múltiplas formas de exploração das imagens e dos personagens esportivos se apresentam a cada dia. Programas retrospectivos, "os melhores momentos", "os gols da rodada", entrevistas com jogadores e atletas, debates com especialistas, são tipos tradicionais de exploração midiática do fenômeno esportivo. A principal forma de notícia vinculada ao futebol feminino, quando mostrado em canal aberto, é uma matéria de curta duração mostrando "os gols da rodada", focando principalmente nas fases finais das competições. Os gols são reproduzidos, sem comentários dos especialistas e de maneira rápida. As reportagens gravadas com entrevistas são raras nessa modalidade. Por outro lado, o futebol masculino esbanja reportagens diárias. Comentários sobre jogadores e jogos, matérias gravadas com jogadores e técnicos, análise sobre os jogos com comentaristas de diferentes áreas de atuação são o foco. Ainda contam com cobertura diária de treinos e concentração dos jogadores em pré-jogos. 
Frente ao exposto, os patrocinadores investem no sucesso destes programas, das equipes e jogadores de destaque, para divulgar e vender mais os seus produtos. Os clubes, as equipes, os jogadores e atletas, por sua vez, aproveitam as chances de aparecer diante da grande massa de telespectadores para se tornarem mais conhecidos, mais populares, garantirem patrocínio e auferir maiores lucros (KENSKI, 1995). A ética esportiva alterou-se do ideal de que "o importante é competir" e transformou-se em um novo ideal em que "tão importante quanto competir é vencer, é ser conhecido, ser famoso, aparecer e lucrar" (KENSKI, 1995).

A emissora líder em audiência atinge 99,62\% dos domicílios com televisão em todo o território nacional. É assistida por mais de 200 milhões de pessoas diariamente, sejam elas no Brasil ou no exterior. Esta emissora, a Rede Globo, é a segunda maior rede de televisão comercial do mundo, atrás apenas da norte-americana "American Broadcasting Company (ABC)". No estado do Rio Grande do Sul, a Rede Brasil Sul de Televisão, pertencente ao grupo RBS, possui doze emissoras afiliadas a Rede Globo, tendo a cobertura de todo o estado. Esta, possui o telejornal esportivo chamado Globo Esporte, exibido nas tardes de segunda-feira a sábado com 30 minutos de duração, tendo a maior audiência desde 2009, com uma média de 548 mil pessoas alcançadas por programa na Grande Porto Alegre. As atualizações esportivas visam, principalmente, às partidas da dupla Sport Club Internacional e Grêmio Futebol Porto-Alegrense - disputas conhecidas como "GreNal" - e as novidades sobre outros times do estado. Desta forma, o futebol feminino, em algumas oportunidades, faz parte desta programação. Este estudo partiu do pressuposto de que o novo regulamento da CONMEBOL - que seria implementado no ano de 2019 - e o retorno do futebol feminino a dupla GreNal, promoveriam um aumento gradual do número de reportagens exibidas neste espaço do esporte televisivo.

\section{Regulamento da Conmebol}

A Confederação Sul-Americana de Futebol (Conmebol) é uma instituição esportiva internacional que organiza, desenvolve e controla competições de futebol. Os campeonatos mais conhecidos são a Conmebol Libertadores e Sul-Americana, disputados por clubes, e a Conmebol Copa América, disputada por seleções. A entidade foi criada em nove de julho de 1916, quando as confederações da Argentina, Chile, Uruguai e Brasil se uniram e fundaram a CONMEBOL. Posteriormente, outras confederações filiaram-se à Conmebol, o 
Paraguai em 1921, o Peru em 1925, a Bolívia em 1926, o $\quad$ Equador em 1927, a Colômbia em 1936, e, por fim, a Venezuela em 1952 (CONMEBOL, 2018).

A CONMEBOL divulgou, em 2016, o seu novo estatuto e regulamento de licença de clubes, trazendo uma série de normas novas às confederações afiliadas à entidade. De tal modo, para disputar a Copa Sul-Americana ou a Libertadores, as equipes passaram a ter que se adequar às regras de licenciamento. A CONMEBOL deu um prazo de dois anos para adaptação, uma vez que a medida passaria a valer a partir de 2019 (BARLEM, 2018).

O documento se adequa ao artigo 23 do estatuto da Federação Internacional de Futebol (FIFA), que obriga às confederações a ter medidas de governança que incluem, dentre outros itens, controle antidopagem, neutralidade política e religiosa e, principalmente, a incorporação de artigos que preveem a igualdade de gênero. Para obter a licença da CONMEBOL, um clube deverá ter um time feminino ou se associar a um que o tenha (BARLEM, 2018). O regulamento prevê: o solicitante (à licença) deverá ter uma primeira equipe feminina ou associar-se a um clube que já possua equipe feminina. Além do mais, deverá ter, pelo menos, uma categoria juvenil feminina ou, igualmente, associar-se a um clube que possua. Em ambos os casos, o solicitante deverá prover de suporte técnico e de todo o equipamento e infraestrutura (campo de jogo para a disputa de jogos e treinos) necessária para o desenvolvimento de ambas as equipes em condições adequadas. Finalmente, se exige que ambos os times participem de competições nacionais e regionais, autorizadas pela respectiva associação membro (CONMEBOL, 2016).

\section{Sport Club Internacional e o futebol feminino}

O Sport Club Internacional possui certa tradição no futebol feminino. O Clube deu início às atividades da modalidade em 1984 e, em 1987, conquistou o terceiro lugar no campeonato brasileiro. Durante vários anos não existiram relatos no Rio Grande do Sul de outra instituição com a estrutura do Sport Club Internacional, apoiando a prática do futebol entre as mulheres. Em 1996, por iniciativa de Eduarda Luizelli - conhecida como Duda -, o Sport Club Internacional retomou a equipe feminina para, em 2000, sagrar-se campeão da Copa Sul. No ano seguinte, foi bicampeão, campeão da Copa Cidade de Gravataí e terceiro lugar no Campeonato Brasileiro (BICCA, 2016).

Com todos os resultados positivos alcançados ao longo das temporadas, as atletas do clube também foram convocadas para a seleção brasileira. As primeiras convocadas, em 1999, foram Sônia e Maria. Depois, em 2002, Priscilla, Solange, Rosana Maria e Karina foram 
chamadas. No mesmo ano, o Sport Club Internacional conquistou o tetracampeonato gaúcho, após jogar a final com o Grêmio Futebol Porto-Alegrense (BICCA, 2016). Em 2003, o Sport Club Internacional foi campeão dos Jogos de Porto Alegre nas categorias mirim, infantil e juvenil e vice-campeão na categoria infanto. A equipe adulta foi tricampeã do Metropolitano e campeã brasileira com a equipe infantil, bem como vice-campeã brasileira, com o time infanto-juvenil, campeã do Torneio Emancipação, em Novo Hamburgo, e pentacampeã gaúcha. Em 2004, o Sport Club Internacional, mais uma vez, cedeu atletas para a Seleção Brasileira: Rosana e Solange foram convocadas para formar a equipe que disputaria os Jogos Olímpicos de Atenas, em 2004 (BICCA, 2016).

Após um período sem atividades, o departamento de futebol feminino foi reativado em 2017, vinculado à vice-presidência de Relacionamento Social e tendo a ex-atleta Eduarda Luizelli como coordenadora técnica e Tatiele Silveira na função de treinadora. No mesmo ano, as atletas do Sport Club Internacional venceram o Campeonato Gaúcho de Futebol Feminino ao disputar a final com o Grêmio Futebol Porto-Alegrense. Em 2018, chegaram à semifinal do Brasileirão A2 e disputaram o Campeonato Gaúcho de Futebol Feminino no segundo semestre (BICCA, 2016).

\section{Grêmio Futebol Porto-Alegrense e o futebol masculino}

O Grêmio Futebol Porto-Alegrense deu início às atividades de futebol feminino em 1997 e participou de seis edições do Campeonato Gaúcho de 1997 a 2002, tendo sido bicampeão nos anos de 2000 e 2001, e vice-campeão em outras três oportunidades: 1998, 1999 e 2002. O clube participou da Copa do Brasil de Futebol Feminino em três oportunidades, nos anos de 1998, 2000 e 2001, sendo o seu melhor resultado, o quarto lugar em 2001. Nos anos de 2003 até 2016, o clube não participou do campeonato, voltando com a equipe feminina em 2017.

Em 2013, a Confederação Brasileira de Futebol (CBF), em parceria com a Caixa Econômica Federal, fez a primeira edição do Campeonato Brasileiro de Futebol Feminino, com a participação das 20 melhores equipes do Ranking da CBF. O Grêmio Futebol PortoAlegrense participou, pela primeira vez, da quinta edição, realizada em 2017, tornando-se o primeiro clube gaúcho a participar desta competição. Em 2017, o Grêmio Futebol PortoAlegrense apresentou o time que disputou o Campeonato Brasileiro Feminino Série A1. Em parceria com a Associação Gaúcha de Futebol Feminino, o "tricolor" - como é popularmente conhecido o clube - estava pronto para a competição. O time foi comandado pela técnica 
Patrícia Gusmão, que treinava a Seleção Gaúcha de Futebol Feminino. No Campeonato Gaúcho de 2017, o clube teve como artilheira a jogadora Karina Balestra, conquistando o vice-campeonato.

Na coordenação do Departamento de Futebol Feminino esteve Yura, ídolo do Grêmio que na década de 1970 foi marcante na arrancada tricolor, e, mais recentemente, atuou no sentido de dar destaque à modalidade feminina. Na temporada de 2018, o clube efetivou o departamento de futebol feminino e disputou o Campeonato Brasileiro Feminino Série A2, terminando a disputa em quinto lugar e não avançando para a fase semifinal. No segundo semestre, o clube disputou o Campeonato Gaúcho de Futebol Feminino.

\section{Regulamento, obrigatoriedade e as mulheres do futebol na mídia}

Neste tópico são apresentadas as informações associadas as unidades de significado elaboradas a partir dos dados coletados, seguidas pela sua discussão. Identificou-se que no ano de 2016 houve somente quatro matérias sobre futebol feminino no Globo Esporte do Rio Grande do Sul. Em 2017, houve um crescimento do número de reportagens, totalizando 25. Podemos observar que houve um aumento de $84 \%$ no número de reportagens quando comparados os dois anos. Com relação ao tempo dedicado ao assunto futebol feminino, observou-se que no ano de 2016 foi de 12 minutos e 30 segundos, enquanto no ano de 2017 , foi de 1 hora 3 minutos e 39 segundos, representando um acréscimo de, aproximadamente, $80 \%$.

A tabela de número um apresenta a data da reportagem, o assunto abordado e se foram realizadas entrevistas com as atletas ou comissão técnica. As matérias realizadas com o futebol feminino em 2016 foram todas no mês de março, sendo três matérias realizadas com a mesma atleta, e outra realizada na cidade de Pelotas/RS, apresentando as atletas convocadas para a Seleção Brasileira de Futebol Feminino de Base. No mês de agosto deste ano, a transmissão do Globo Esporte, em função dos Jogos Olímpicos de 2016, deixou de ser regional e se tornou nacional. O Globo Esporte Nacional aumentou a visibilidade para as mulheres, talvez, devido ao crescimento da Seleção Brasileira Feminina nos jogos e ao insatisfatório desempenho inicial da Seleção Brasileira Masculina. Com isso, neste período, um maior número reportagens foram realizadas.

Em 2017, o Globo Esporte Rio Grande do Sul criou o quadro "Joga que nem mulher". De tal modo, a partir de janeiro deste ano ocorreram 25 reportagens com clubes, na sua maioria, entrevistando atletas e comissão técnica ou mostrando os melhores momentos dos 
jogos do Campeonato Brasileiro Série A1 e do Campeonato Gaúcho. Observa-se que no ano de 2017, houve seis vezes mais reportagens do que em 2016. Durante a coleta dos dados, foi possível observar que em alguns estados do Brasil o programa Globo Esporte da região confere maior visibilidade ao futebol feminino, visto pelo número de reportagens com os times. Outrossim, a mídia digital online "www.globoesporte.com" apresenta um número expressivo de reportagens quando comparado a outros meios de comunicação.

Tabela 1 - Data, tempo de duração, assunto abordado e tipo de reportagem no Globo Esporte Rio Grande do Sul no período de 2016 e 2017.

\begin{tabular}{|c|c|c|c|}
\hline Data & Tempo & Assunto & Tipo \\
\hline 8.03 .2016 & $3: 17$ & $\begin{array}{l}\text { Esporte Clube Pelotas revela atletas para } \\
\text { Seleção Brasileira de Futebol Feminino }\end{array}$ & Com entrevista \\
\hline 17.03.2016 & $1: 14$ & $\begin{array}{l}\text { Malu fala sobre as dificuldades da base } \\
\text { no futebol feminino }\end{array}$ & Com entrevista \\
\hline 17.03 .2016 & $3: 23$ & $\begin{array}{l}\text { Joias da base do Inter tem irmã na } \\
\text { Seleção sub-17 }\end{array}$ & Com entrevista \\
\hline 18.03 .2016 & $4: 36$ & $\begin{array}{l}\text { Irmãos gaúchos se destacam em Seleções } \\
\text { de base }\end{array}$ & Com entrevista \\
\hline 07.01 .2017 & $1: 22$ & $\begin{array}{l}\text { Globo Esporte RS lança série "Joga que } \\
\text { nem mulher" na próxima segunda }\end{array}$ & Sem entrevista \\
\hline 09.01 .2017 & $5: 37$ & $\begin{array}{l}\text { Apaixonada por futebol, Giulia rompe } \\
\text { estereótipo e integra time de meninos }\end{array}$ & Com entrevista \\
\hline 10.01.2017 & $6: 13$ & $\begin{array}{l}\text { Pequena Giulia ganha dicas de jogadora } \\
\text { que marcou o futebol feminino no RS }\end{array}$ & Com entrevista \\
\hline 11.01 .2017 & $8: 27$ & $\begin{array}{l}\text { Giulia acompanha final do Campeonato } \\
\text { Estadual de Futebol Feminino }\end{array}$ & Com entrevista \\
\hline 20.01.2017 & $2: 20$ & $\begin{array}{l}\text { Campeonato Brasileiro A1- Grêmio. } \\
\text { Nova divisão de clubes Serie A1 e A2 }\end{array}$ & Sem entrevista \\
\hline 14.02 .2017 & $4: 38$ & $\begin{array}{l}\text { Grêmio é o representante Gaúcho no } \\
\text { Campeonato Brasileiro de Futebol } \\
\text { Feminino }\end{array}$ & Com entrevista \\
\hline 23.02.2017 & 1:09 & $\begin{array}{l}\text { "Joga que nem mulher": Inter lança } \\
\text { departamento de futebol feminino }\end{array}$ & Com entrevista \\
\hline 08.03.2017 & $3: 28$ & $\begin{array}{l}\text { Pelotas recebe visita de treinadora carioca } \\
\text { que atua nos EUA }\end{array}$ & Com entrevista \\
\hline 09.03.2017 & $0: 23$ & $\begin{array}{l}\text { No dia da mulher, Inter apresenta time de } \\
\text { futebol feminino }\end{array}$ & Sem entrevista \\
\hline 13.03.2017 & $2: 58$ & $\begin{array}{l}\text { Gurias do Grêmio estreiam com vitória no } \\
\text { Campeonato Brasileiro de Futebol } \\
\text { Feminino }\end{array}$ & Com entrevista \\
\hline 27.03.2017 & $0: 19$ & $\begin{array}{l}\text { Time feminino do Grêmio perde para o } \\
\text { Corinthians no Brasileirão }\end{array}$ & Sem entrevista \\
\hline 28.03.2017 & $2: 35$ & $\begin{array}{l}\text { Equipe feminina de futsal do interior do } \\
\text { RS terá segunda geração }\end{array}$ & Com entrevista \\
\hline
\end{tabular}




\begin{tabular}{|c|c|c|c|}
\hline 30.03 .2017 & $0: 17$ & $\begin{array}{l}\text { Grêmio perde para o Iranduba-AM no } \\
\text { Brasileirão Feminino }\end{array}$ & Sem entrevista \\
\hline 04.04 .2017 & $1: 13$ & $\begin{array}{l}\text { Grêmio perde para o Audax no } \\
\text { Brasileirão feminino }\end{array}$ & Sem entrevista \\
\hline 17.05 .2017 & $2: 32$ & $\begin{array}{l}\text { "Joga que nem mulher" conheça o projeto } \\
\text { "Andressinha" que incentiva o futebol } \\
\text { feminino }\end{array}$ & Com entrevista \\
\hline 14.06 .2017 & $0: 19$ & $\begin{array}{l}\text { Meia do Inter é convocada para Seleção } \\
\text { Brasileira feminina sub-17 }\end{array}$ & Sem entrevista \\
\hline 01.08 .2017 & $4: 27$ & $\begin{array}{l}\text { Isadora: a zagueira artilheira do time do } \\
\text { Internacional }\end{array}$ & Com entrevista \\
\hline 02.08 .2017 & $3: 57$ & $\begin{array}{l}\text { Escolinha de Futebol do Grêmio é o } \\
\text { pontapé inicial para jovem de } 12 \text { anos }\end{array}$ & Com entrevista \\
\hline 03.08 .2017 & $3: 48$ & $\begin{array}{l}\text { Em véspera do Gauchão, equipe feminina } \\
\text { do interior tem goleira de } 13 \text { anos e outra } \\
\text { de } 35 \text { anos }\end{array}$ & Com entrevista \\
\hline 04.08 .2017 & $4: 23$ & $\begin{array}{l}\text { Última reportagem da série "Joga que } \\
\text { nem mulher" }\end{array}$ & Com entrevista \\
\hline 07.08 .2017 & $0: 21$ & $\begin{array}{l}\text { Zagueira artilheira do Inter marca gol do } \\
\text { título na final do Estadual sub-17 }\end{array}$ & Sem entrevista \\
\hline 14.08 .2017 & $0: 24$ & $\begin{array}{l}\text { Inter vence na estreia do Gauchão } \\
\text { feminino diante do Estrela }\end{array}$ & Sem entrevista \\
\hline 21.08 .2017 & $0: 40$ & $\begin{array}{l}\text { Grêmio e Inter vencem no Gauchão } \\
\text { feminino }\end{array}$ & Sem entrevista \\
\hline 09.10 .2017 & $0: 36$ & $\begin{array}{l}\text { Por falta de atletas partida entre Grêmio e } \\
\text { Palestra de Carazinho é interrompida }\end{array}$ & Sem entrevista \\
\hline 11.12 .2017 & $1: 13$ & $\begin{array}{l}\text { Time feminino do Inter vence o Grêmio e } \\
\text { é campeão gaúcho } 2017\end{array}$ & Com entrevista \\
\hline
\end{tabular}

Fonte: Autoria própria (2019).

Os resultados deste estudo mostraram que as matérias realizadas com o futebol feminino, no Globo Esporte Rio Grande do Sul, em 2016, foram quatro no mês de março, sendo que $75 \%$ destas ocorreram com a mesma atleta. Somente $25 \%$ foram referentes a atletas convocadas para a Seleção Brasileira de Futebol Feminino de Base. No período dos Jogos Olímpicos de 2016, o programa deixa de ser regional e passa a ser o Globo Esporte Nacional. Em consonância aos resultados encontrados neste estudo, cabe referir que o IBOPE Repucom observou que a partir das Olimpíadas de 2016, no estado do Rio de Janeiro, o futebol feminino foi o esporte que mais teve audiência entre os menos populares. Se antes dos Jogos Olímpicos o interesse era de $34 \%$, passou a ter mais da metade do interesse dos internautas, chegando à casa dos 51\%, pós-período olímpico. O jogo entre Brasil e Austrália pelas quartas de final da competição teve o público de 22,5 milhões, sendo a quarta maior audiência dentro da programação televisiva do evento. É possível observar que a mídia televisiva teve o 
potencial de despertar uma maior atenção do público e aumentar o número de simpatizantes para o futebol feminino, considerando-se, principalmente, o desempenho da seleção (NASSIF, 2016).

Santana e Badiali (2017), observaram que na participação da Seleção Feminina de Futebol nos Jogos Olímpicos, entre os dias 3 e 20 de agosto, o site Sportv ampliou em mais da metade as publicações sobre o futebol feminino em relação ao período anterior. Resultado esperado, visto que os Jogos Olímpicos se constituíram historicamente em um evento de êxito para a seleção feminina. No conteúdo das matérias, algumas reportagens sobre atletas que tiveram destaque nos jogos, outras com cobertura das disputas em que a seleção atuou, e quatro, em especial, que tinham relação com outros atletas da delegação brasileira, que de alguma maneira ligavam-se no discurso com a atuação das mulheres do futebol.

Após o término dos Jogos Olímpicos, a medida tomada para incentivar o futebol feminino tornou obrigatório um time de mulheres nos clubes de futebol que desejam disputar a Copa Libertadores da América ou a Copa Sul- Americana. A decisão partiu de um licenciamento em conjunto entre a CBF, a FIFA e a CONMEBOL e começou a valer a partir de 2019. Dos vinte clubes que disputariam a Série A do Campeonato Brasileiro (que é uma das formas de se conseguir vaga para a Copa Libertadores), somente oito possuíam times femininos naquela época. Além dos times em si, as exigências feitas pela sanção dada pelas instituições também se referem à estrutura dos clubes e a profissionalização do futebol feminino (TELLES, 2017).

Embora tenha sido identificada uma tendência de valorização do futebol feminino, esta mostrou ser transitória, sazonal e efêmera, atendendo principalmente a uma demanda decorrente dos Jogos Olímpicos e da conquista que a equipe brasileira de futebol feminino alcançou, conforme Martins e Moraes (2007). Mais recentemente, a visibilidade que a mídia proporcionou ao futebol feminino, mesmo que pequena, trouxe uma expectativa de melhora no que diz respeito à cobertura midiática das competições. O que, de certa forma, pode ser visto na tabela de número um, a qual apresenta o tempo de duração das reportagens. Comparando os anos de 2016 e 2017, nota-se que houve um aumento de aproximadamente $80 \%$ no tempo de duração das reportagens dedicadas ao futebol feminino no programa televisivo investigado.

Um fator que colaborou para o crescimento de reportagens com o tema e uma maior visibilidade ao esporte foi o fato de que os principais clubes de futebol do Rio Grande do Sul - o Grêmio Futebol Porto-Alegrense e o Sport Club Internacional -, como forma de se adaptarem ao novo regulamento da CONMEBOL, reativaram os seus departamentos de 
futebol feminino. A isto, a mídia respondeu com a criação do quadro "Joga que nem mulher". $\mathrm{O}$ crescimento de reportagens representou uma maior visibilidade à modalidade do futebol feminino, com o paralelo aumento de interesse de espectadores.

A tabela número um também mostra o assunto abordado nas reportagens e se foram realizadas entrevistas com as atletas ou comissão técnica. No ano de 2017, foram 25 reportagens realizadas sobre o futebol feminino. A maioria das reportagens envolveu entrevista com as atletas ou comissão técnica, apresentando incremento na quantidade e na qualidade das reportagens em relação ao ano de 2016. As reportagens foram associadas ao Campeonato Brasileiro Série A1 e ao Campeonato Gaúcho. Para Patiño (2011), apesar de caminhar a passos lentos, a gradual inserção das mulheres do futebol nos ambientes de comunicação de massa contribui para que as suas potencialidades esportivas sejam reconhecidas no meio social, promovendo-se, em longo prazo, ressignificações acerca de representações estereotipadas que ainda permeiam o universo do futebol feminino.

O esporte ganha mais atenção do público e mais adeptos quando se torna televisivo e isso acontece se o público, em primeiro lugar, já tiver algum interesse na modalidade. Para que o investimento por parte das empresas de telecomunicação ocorra, o esporte a ser transmitido e divulgado deve ser capaz de trazer audiência (PROCKNICH, 2010). O poder da mídia influencia o crescimento do esporte e a associação entre esses setores tem como consequência o aumento do público aficionado na modalidade transmitida, o que gera lucros para seus patrocinadores e também na venda de cotas para anunciantes que querem atingir os fãs em frente à televisão, pois enquanto estes torcem para seu time também tem acesso a sugestões de consumo (MORAES, 2008).

O baixo interesse das emissoras de televisão na compra dos direitos de imagem dos jogos e o número de patrocínios dos times femininos interferem na mídia. É possível observar que um aumento da visibilidade do futebol feminino nas mídias acontece, com maior frequência, naqueles estados onde o futebol masculino não possui um time de tradição. Por exemplo, o estado de Manaus/AM não possui times masculinos, disputando as principais divisões do Campeonato Brasileiro. De tal modo, o time feminino, denominado Iranduba, apresenta amplo destaque, jogando e lotando o estádio Arena da Amazônia - Vivaldo Lima, com público aproximado de 20 mil pessoas nos principais jogos. Na imprensa local, três fatores são apontados como primordiais para o sucesso de público nos jogos do Iranduba em casa: o crescimento técnico do time, a atenção que a mídia local fornece ao futebol feminino e a visita de times tradicionais para disputar partidas na região. Nesse sentido, um importante 
passo para a popularização da modalidade seria unir a mídia e as arquibancadas cheias, o que colaboraria para atrair novos patrocinadores.

Cabe mencionar que, para as mulheres, ainda "são grandes os desafios no campo do futebol, pois para entrar no espaço público do futebol de forma eficaz é necessário romper as influências da resistência à subjetivação feminina" (PATIÑO, 2011, p. 141). Por outro lado, destaca-se que esta quebra de paradigmas já está em movimento, com mulheres engajadas tanto como atletas nos campos de jogos quanto nos veículos de comunicação, exercendo papeis distintos em programas esportivos. Viviana Vila é uma destas mulheres, a qual começou a desenvolver o trabalho de comentarista de futebol em uma rádio argentina e, posteriormente, se tornou a primeira mulher de língua espanhola a comentar uma Copa - a Copa da Rússia (IZQUIERDO, 2018). Outro exemplo, é Fabíola Andrade, que relatou: “Aqui no Brasil ainda não conseguimos formar, ou não tivemos espaço para narradoras e comentaristas". [...] Somos repórteres, apresentadoras, produtoras e editoras apenas" (IZQUIERDO, 2018). Ainda, Fabíola Andrade frisou: “Tenho muito orgulho de fazer parte de uma geração que pode e deve mudar esse cenário do mundo esportivo". Para ela, um veículo de comunicação configura-se em um serviço completo quando consegue igualar o número funcionários dos sexos feminino e masculino.

\section{Considerações finais}

Este estudo buscou identificar a ocorrência e as características das reportagens sobre o futebol feminino no programa de televisão "Globo Esporte - Rio Grande do Sul”, nos anos de 2016 e 2017. Nesse sentido, foi possível observar que houve aumento do espaço no referido programa para o futebol feminino do Rio Grande do Sul após a divulgação das mudanças que ocorreriam no regulamento da CONMEBOL. O incremento na visibilidade pôde ser identificado pelo maior número e pelo tipo de reportagens realizadas, além de ter sido criado um quadro específico para abordar o futebol feminino, contemplando, inclusive, a participação de jogadoras mulheres em edições do programa de televisão.

O espaço ao futebol feminino na mídia, possivelmente, foi ampliado com o início da obrigatoriedade do regulamento da CONMEBOL, em 2019. Nesta perspectiva, ressalta-se a potencialidade de se realizar novos estudos sobre o assunto no período que advém este marco do futebol feminino brasileiro. De modo a avançar na discussão iniciada nesse estudo, cabe assinalar a necessidade de se olhar e problematizar aspectos socioculturais que atravessam o desenvolvimento do futebol feminino, tanto no âmbito do alto rendimento como fora dele. 


\section{Referências bibliográficas}

AGUIAR, Leonel Azevedo de; PROCHNIK, Luisa. Quanto vale uma partida de futebol? A relação entre televisão e futebol no cenário midiático contemporâneo. LOGOS 33 Comunicação e Esporte, v. 17, n. 2, 2º semestre, 2010.

ALBUQUERQUE, Naiara. No país do futebol, as mulheres jogam com menos: falta salário, público e estrutura, 28 mai. 2017. Disponível em: https://www.nexojornal.com.br/reportagem/2017/05/28/No-pa\%C3\%ADs-do-futebol-asmulheres-jogam-com-menos-falta-sal\%C3\%A1rio-p\%C3\%BAblico-e-estrutura. Acesso em: 25 ago. 2018.

BARLEM, Cíntia. Conmebol diz que regra de times femininos será cumprida; clubes buscam regularização junto à $C B F, 15$ ago. 2018. Disponível em: https://globoesporte.globo.com/blogs/dona-do-campinho/post/2018/08/15/conmebol-diz-queregra-de-times-femininos-sera-cumprida-clubes-buscam-regularizacao-junto-a-cbf.ghtml. Acesso em: 24 set. 2018.

BICCA, Ana Maria Froner. Futebol feminino: pioneirismo no Internacional, Out. 2016. Disponível em: http://memoriadointer.blogspot.com/2016/10/futebol-feminino-pioneirismono.html. Acesso em: 24 set. 2018.

COIMBRA, Cecília Maria Bouças. Mídia e produção de modos de existência. Psicologia: Teoria e Pesquisa, Brasília, v.17, n.1, abr. 2001.

CONFEDERAÇÃO SUL-AMERICANA DE FUTEBOL. Regulamento, 15 jan. 2015. Disponível em: http://www.conmebol.com/es/estatuto. Acesso em: 25 ago. 2018.

FLICK, Urie. Introdução à pesquisa qualitativa. Tradução Joice Elias Costa. 3 ed. Porto alegre: Artmed, 2009.

IG SÃO PAULO. Segundo o censo de 2010, aparelhos de televisão estão em mais de 95\% dos domicílios brasileiros, 24 abr. 2012. Disponível em: https://ultimosegundo.ig.com.br/brasil/2012-04-27/ibge-pela-1-vez-domicilios-brasileirostem-mais-tv-e-geladeira-d.html. Acesso em: 24 set. 2018.

IZQUIERDO, Puntero. "Cartas de março"; mulheres contam suas histórias no futebol, 28 mai. 2018. Disponível em: https://medium.com/puntero-izquierdo/cartas-de-mar\%C3\%A7omulheres-contam-suas-hist\%C3\%B3rias-no-futebol-50461a9cbff6. Acesso em: 26 fev. 2020.

KENSKI, Vani M. O impacto das mídias e das novas tecnologias de comunicação na Educação Física. Revista Motriz, Rio Claro, v. 1, n. 2, p. 129-133, dez. 1995.

MARTINS, Leonardo Tavares; MORAES, Laura. O futebol feminino e sua inserção na mídia: a diferença que faz uma medalha de prata. Pensar a Prática, Goiás, v. 10, n. 1, p. 6981, jan./jun., 2007.

MAZZOCATO, Ana Paula Facco; et al. A influência do esporte na mídia e no desenvolvimento da sociedade, Mai. 2012. Disponível em: https://home.unicruz.edu.br/mercosul/pagina/anais/2012/Linguagens $\% 20 \mathrm{e} \% 20 \mathrm{desenvolvimen}$ to $\% 20$ socio-

cultural/artigos/a\%20influencia\%20do\%20esporte\%20na\%20midia\%20e\%20no\%20desenvol vimento\%20da\%20sociedade.pdf. Acesso em: 25 ago. 2018.

MORAES, D. Cultura tecnológica, mídia e consumo globalizado. In: BRITTOS, Valério Cruz; CABRAL, Adílson (Orgs.). Economia Política da Comunicação: interfaces brasileiras. Rio de Janeiro: E-papers serviços editoriais, 2008. 
NASSIF, Mohamed. Após os Jogos Olímpicos, cresce o interesse em modalidades no Brasil, 22 dez. 2016. Disponível em: https://www.torcedores.com/noticias/2016/12/apos-os-jogosolimpicos-cresce-o-interesse-em-modalidades-no-brasil. Acesso: 25 ago. 2018.

PATIÑO, Jorge Humberto Ruiz._El fútbol femenino: una mirada desde lo público y lo privado. Revista da ALESDE - Associação Latinoamericana de Estudios Socioculturales del Deporte. Curitiba, v. 1, n. 1, p. 129-142, setembro, 2011.

SANTANA, Amanda Monique Porfírio Ribeiro de; BADIALI, Michelle Ferret. A Visibilidade do Futebol Feminino no Brasil: uma análise descritiva das publicações do Sportv e Planeta Futebol Feminino. Intercom - Sociedade Brasileira de Estudos Interdisciplinares da Comunicação, XIX Congresso de Ciências da Comunicação na Região Nordeste, Fortaleza/CE, jun./jul., 2017.

SECRETARIA DE COMUNICAÇÃO SOCIAL DA PRESIDÊNCIA DA REPÚBLICA SECOM. Pesquisa Brasileira de Midia 2016, 29 ago. 2016. Disponível em: http://www.pesquisademidia.gov.br/files/E-Book_PBM_2016.pdf. Acesso em: 24 set. 2018.

TELLES, Gabriela Pereira. País do Futebol...feminino? A (In)Visibilidade das Mulheres Nas Quatro Linhas. 2017. 65 f. Trabalho de Conclusão de Curso (Graduação em Comunicação Habilitação em Jornalismo) - Escola de Comunicação, Universidade Federal do Rio de Janeiro, Rio de Janeiro, 2017. 